\title{
Change and stability in loneliness and friendship after an intervention for older women
}

\author{
CAMILLE M. S. MARTINA*, NAN L. STEVENS $\dagger$ and \\ GERBEN J. WESTERHOF!
}

\begin{abstract}
In this study we examine patterns of change and stability in loneliness among 108 women who had participated in a friendship enrichment programme during the year after the programme. We distinguished seven groups of participants in which different levels of loneliness significantly declined, remained stable or increased. These were reduced to the following groups: those recovered, significantly improved and not improved. We then examined whether resources such as age, education, partner status, health, initially available friendships and developments in friendships were related to these loneliness patterns. The data were collected using face-to-face semi-structured interviews, a loneliness scale and the personal convoy model. The results indicate that none of the demographic characteristics, nor health, were associated with the patterns of loneliness. Friendship availability and development did differ among the groups. Recovery from loneliness after a year was associated with the presence of a friend in the outer circle of the convoy and having more variation in one's friendships initially and one year later. It was also associated with the presence of a friend in the inner circle and reporting improvement in friendship later. The absence of these qualities initially or subsequently was more characteristic of those whose loneliness was stable or increased. Thus, the maintenance of companionate friendship and the development of intimacy in one's friendships seem advantageous for recovery from loneliness. While this study illustrates that recovery from, and significant reduction of loneliness are possible, we are not yet able to predict who will benefit and who will not benefit from a friendship enrichment programme.
\end{abstract}

$\boldsymbol{K E Y} \boldsymbol{W O R D S}$ - loneliness, friendship, intervention, older women.

* Department of Developmental Psychology \& Psychogerontology, Radboud University, Nijmegen, The Netherlands.

$\dagger$ Behavioural Science Institute, Radboud University, Nijmegen, The Netherlands.

$\$$ Department of Psychology, Health and Technology, University of Twente, Enschede, The Netherlands. 


\section{Introduction}

The negative consequences of loneliness in later life have become increasingly clear during the last decade (Hawkely and Cacioppo 2007, 2010). Loneliness is 'the unpleasant experience that occurs when a person's network is deficient in some way, either quantitatively or qualitatively' (Peplau and Perlman 1982: 3). Those older adults who suffer from enduring loneliness are more likely to have health problems involving high blood pressure, heart disease and poor quality of sleep; they also demonstrate more unhealthy behaviour, evident in higher rates of smoking and alcohol abuse. Hawkley and Cacioppo (2007) conclude that loneliness accelerates physical decline with age, increasing morbidity and mortality. A more recent longitudinal study demonstrated reciprocal effects between loneliness and health outcomes, such as depressive symptoms and functional limitations (Luo et al. 2012). It also becomes more difficult for older adults to develop strategies to reduce loneliness once it has stabilised, because severe loneliness interferes with cognitive functioning (Cacioppo and Patrick 2008).

In later life, loneliness is often triggered by the loss of close relationships and by changes in health that interfere with maintaining social relations (Pinquart and Sörensen 2001a). Other factors such as a restricted social network, poor social skills and negative social cognitions often contribute to the perpetuation of loneliness among older adults (Cacioppo and Patrick 2008; Cohen-Manfield and Parpura-Gill 2007; De Jong Gierveld 1998). While experiencing occasional loneliness is inevitable in later life, an important priority of older adults themselves and of educational programmes should be to prevent loneliness from becoming chronic and self-perpetuating, in order to avoid or reduce its negative consequences.

Friends are valuable resources to help maintain wellbeing and reduce the risk of loneliness in later life (Chen and Feeley 2014; Huxhold, Miche and Schuz 2013; Pinquart and Sörenson $2001 a$, $2001 b$; Stevens and Westerhof 2006). Because friendship is a voluntary, reciprocal relationship, it is usually a source of pleasurable companionship, reassurance of worth and emotional support (Hartup and Stevens 1997). As unsatisfactory friendships can be discontinued, the quality of friendships is often higher than the quality of family relationships, though both types are important for wellbeing. Studies on social network typologies indicate that more diverse networks which include friends as well as family are associated with higher levels of happiness and resilience, and lower levels of depression, anxiety and loneliness, than are more restricted networks (Fiori, Antonucci and Cortina 2006; Litwin and Shiovitz-Ezra 2010). Despite these beneficial effects, friendship becomes more scarce in later life since friendship 
networks tend to decrease in size throughout adulthood (Wruz et al. 2013), and contact with friends often declines as one ages (Shaw et al. 2007).

The Friendship Enrichment Programme (FEP) is an intervention designed in the Netherlands to help women, aged 55 and older, improve their wellbeing and reduce their (risk of) loneliness by improving their relational competence and developing the friendships that they desire (Stevens 2001). The two components of relational competence that focus on developing new relationships and enhancing existing relationships are central to the design of the programme. Both components are considered important in order to compensate for the losses that naturally occur in social networks as people age (Hansson, Daleiden and Hayslip 2004; Wruz et al. 2013). Women were chosen as the target of this programme because they are also more likely to experience conditions related to loneliness (e.g. widowhood, living alone, chronic health problems and greater functional limitations), compared to older adult men (De Jong Gierveld 1998; Pinquart and Sörensen 2001 b; Sonnenberg et al. 2000). Also women tend to remain interested in, and capable of, developing new friendships as they age (Stevens and Van Tilburg 2011).

The FEP helps participants clarify their needs, desires and expectations in friendship, analyse their current social networks to identify actual and potential friendships, and formulate goals that involve the improvement of existing friendships or the development of new friendships. Participants are assigned tasks and engage in exercises that are related to these goals. Thus, participants practise skills that are important to developing and maintaining friendships of high quality. These skills include listening well, appropriate self-disclosure, setting boundaries in contact, expressing appreciation and dealing with conflict. There is also attention to the improvement of selfesteem throughout the programme. The FEP is therefore future-oriented, encouraging pro-active coping specifically focused on friendship, but also relevant to other social relationships. Bode et al. (2007: 43) define pro-active coping as 'the promotion of desired future outcomes and the prevention of undesired changes'. The emphasis on improving relational competence and social relationships in the FEP also coincides with strategies described by theory on the self-management of wellbeing (Steverink, Lindenberg and Slaets 2005); this theory has proven to be a valuable framework for developing an intervention to reduce loneliness (Kremers et al. 2006; Martina, Stevens and Westerhof 2012 ).

Studies examining the effects of participation in the FEP indicate that the programme attracts women with varying levels of loneliness who are interested in friendship. Over 6o per cent of the participants reported positive developments in friendship within six and 12 months after following the programme. As a group, they demonstrated modest improvement in wellbeing within six months and a reduction of loneliness within $10-12$ 
months after the programme (Martina and Stevens 2006; Stevens, Martina and Westerhof 2006). However, these analyses are based on average scores of participants at different points in time and do not reveal individual differences in outcomes. Therefore, the first goal of this study was to identify different patterns of change or stability in loneliness during the year following the programme. This is the period in which participants are most likely to apply what they have learned in the programme.

A second goal was to examine factors that are associated with differences in loneliness patterns, including demographic factors. It is possible that those with more resources, such as a higher level of education and better health, find it easier to improve their relational competence and to apply this proactively (Ouwehand 2005). We also explored whether age and marital status were related to loneliness patterns. The availability of social resources may also be associated with different patterns of loneliness. Those who already have at least one close or one less close friendship available to partially meet their needs for intimacy and companionship might demonstrate more positive outcomes during the year after the programme than did those who initially lacked these types of friendship.

The specific research questions examined in this study are:

- Research question 1: Which patterns of change and stability in loneliness are evident among participants during the year following the programme? Is it possible to distinguish persons with positive and negative change as well as those with stable loneliness?

- Research question 2: Are background characteristics (e.g. age, education, partner status, health status) related to these changes or stability?

- Research question 3: Are characteristics of friendships that are available at the end of the programme related to changes or stability in loneliness during the year following the programme?

- Research question 4: Are developments in friendships during the year following the programme related to changes or stability in loneliness?

\section{Method}

\section{Design}

To study change and stability in loneliness after participation in the FEP, a secondary analysis of data from two studies was conducted. Study 1 was an unsubsidised pilot study on the FEP that examined developments in friendship by following participants during the year after the programme. There was no baseline measurement. The programme was organised in co-operation with a senior service agency in a Dutch city with a population of 
180,ooo. Participants were recruited by means of folders and newspaper articles on the programme. Data were collected only at the end of the programme and 10-12 months later. The intervention was completed by 72 women; of these, 55 agreed to participate in the first interview ( $76 \%$ response rate). The second interview was completed by $5^{2}$ women; excluding those who dropped out as a result of health limitations or death $(2 \%)$, the non-response was 4 per cent for the second measurement. This study took place between 1995 and 1999 .

Study 2 was funded by a national programme of research on successful ageing and took place between 2001 and 2005. It involved a pre-test-posttest design with a follow-up measurement. The FEP was offered in four Dutch communities by senior service agencies. Participants were recruited in the same way as in Study 1. Sixty-nine of 84 participants in the various FEPs were recruited for the study; the response rate was 82 per cent. In Study 2 there were measurements prior to the programme $\left(T_{\mathrm{o}}\right)$, immediately after the programme $\left(T_{1}\right)$, six months later $\left(T_{2}\right)$ and a year after the programme ended $\left(T_{3}\right)$. For this analysis we only used data from $T_{1}$ and $T_{3}$ since they corresponded to those in Study 1 and covered the year after the programme. There were $5^{6}$ women in the intervention group who completed four measurements. Excluding women who dropped out as a result of health limitations or death $(5 \%)$, there was a non-response rate of 6 per cent immediately following the programme, 2 per cent six months after the programme ended and 7 per cent a year after the programme ended.

Table 1 provides an overview of the participants' background variables and average loneliness in Studies 1 and 2. The participants in Studies 1 and 2 were similar on most background variables except for education and health restrictions. The average age in the two studies was 63.6 and 63 . The marital status in the studies was also comparable, with widowed women outnumbering married and divorced women, and a small group of never married women. About two-thirds of the participants lived alone. Loneliness at the end of the intervention was similarly high in the two studies. A year later participants in Study 1 were significantly less lonely than those in Study 2. The participants of the two studies differed in their educational level: more participants in Study 1 had higher levels of education than those in Study 2. Health restrictions were also different in the two studies: more than two-thirds of the participants $(70 \%)$ in Study 2 reported health restrictions, compared to 42 per cent in Study 1.

\section{Measures}

The data were collected in face-to-face semi-structured interviews during approximately two hours at the participants' home. The interviews included 
TABLE 1. Comparison of the participants' background variables and loneliness in Studies I and 2

\begin{tabular}{|c|c|c|c|}
\hline & Study 1 & Study 2 & $\begin{array}{c}\text { Study } 1 \text { versus } \\
\text { Study } 2^{1}\end{array}$ \\
\hline $\mathrm{N}$ & $5^{2}$ & $5^{6}$ & \\
\hline Age range & $5^{2-80}$ & $53-78$ & \\
\hline \multirow[t]{2}{*}{ Mean age } & $63.6(\mathrm{SD}=6.4)$ & $63(\mathrm{SD}=6.3)$ & $0.5^{2}$ \\
\hline & \multicolumn{2}{|c|}{ Percentages } & \\
\hline \multicolumn{3}{|l|}{ Marital status: } & 1.14 \\
\hline Married & 23 & 27 & \\
\hline Widowed & $4^{\circ}$ & $3^{6}$ & \\
\hline Divorced & 25 & 30 & \\
\hline Never married & 12 & 7 & \\
\hline \multicolumn{3}{|l|}{ Living situation: } & 0.861 \\
\hline Alone & 69 & 68 & \\
\hline With partner & 27 & 27 & \\
\hline Other & 4 & 5 & \\
\hline \multicolumn{3}{|l|}{ Educational level: } & $7 \cdot 17^{*}$ \\
\hline Elementary & 35 & $3^{0}$ & \\
\hline Secondary & 27 & $5^{\mathrm{O}}$ & \\
\hline Higher education & 38 & 20 & \\
\hline \multicolumn{3}{|l|}{ Health restrictions: } & $13 \cdot 77^{*}$ \\
\hline None & $5^{8}$ & 30 & \\
\hline Some restrictions & $3^{8}$ & 43 & \\
\hline Considerable restrictions & 4 & 27 & \\
\hline \multirow[t]{2}{*}{ Loneliness (range $\mathrm{o}-11$ ) } & $6.9^{2}(\mathrm{SD}=3.1)$ & $7.0^{2}(\mathrm{SD}=3.4)$ & -1.83 \\
\hline & $4.1^{3}(\mathrm{SD}=3.1)$ & $6.0^{3}(\mathrm{SD}=3.5)$ & $-3.16^{*}$ \\
\hline
\end{tabular}

Notes: 1. Significance of differences according chi-square test. 2. At the end of the intervention. 3. A year after the intervention ended. SD: standard deviation.

Significance level: $* p<0.05$.

questions on background characteristics such as age, marital status, education level and health impairments.

Loneliness was measured by a loneliness scale ( 11 items) that has proven to be a reliable and valid instrument in surveys with older persons (De Jong Gierveld and Kamphuis 1985; De Jong Gierveld and Van Tilburg 1999). For the present study, the internal consistency of this scale was 0.84 . Scores on the scale range from o (no loneliness) to 11 (severe loneliness); a score between 3 and 8 is an indication of moderate loneliness, while higher scores $\left(9^{-11}\right)$ indicate more severe loneliness.

In order to study friendship and changes in friendship, we used data collected with the personal convoy of relationships (Kahn and Antonucci 1980). The convoy model is a method to map an individual's primary social relationships, while distinguishing different levels of closeness and importance among these relationships. It consists of three circles surrounding the target person. The respondents place those persons who they consider 
as most close and most important to them in the inner circle, those who are less close yet still important in the middle circle, and those even less close and less important in the outer circle. Participants examined their personal convoys at each measurement point and reported on changes that had taken place, especially regarding friendship. Specific questions focused on whether there were new friends in the convoy, and whether existing friendships were assigned new positions in terms of importance and closeness. Both positive and negative types of change were described. The positive changes included making new friends or experiencing improvements in existing friendships, e.g. feeling closer to friends and/or spending more time together. Negative change included the loss of friends due to death or inability to maintain the friendship by either person involved. Another type of negative change was the deterioration in friendship, in which friendships were described as less close and less important for a variety of reasons such as disappointment in, or conflict with, a friend.

\section{Analyses}

Loneliness status. To analyse possible changes and stability in loneliness after participation in the FEP we used a person-oriented approach, rather than a variable-oriented approach (Laursen and Hoff 2006). This type of analysis makes it possible to identify groups sharing similar profiles on key variables, in this case on loneliness at two different points in time. The goal was to identify different patterns of change in loneliness and then examine whether other factors were linked to these patterns. Patterns of change in loneliness were identified by using an exploratory cluster analysis (Ward's Method) on the loneliness scores at the end of the intervention and a year later. Ward's Method was selected because it has proven to be an efficient technique to construct well-defined clusters (Oshri et al. 2008). The most appropriate number of clusters was determined based on the size and distinctiveness of each cluster. The cluster analysis revealed that the seven cluster solutions produced distinctive and homogeneous groupings explaining approximately go per cent of the error sum of squares (indicating that the cluster solution adequately explains the observed data). Then, to distinguish participants with positive and negative change as well as those who had not experienced any change, the clusters were combined in a Recovered group, an Improved group and a Non-improved group.

Background status. To analyse a possible association between background factors and variations in loneliness status, two age groups were computed: younger than $6_{5}$ (o) and $6_{5}$ and older (1). Education was re-coded into primary education (1), secondary education (2) and higher education 
(3). Marital status was re-coded into having a partner (1) or not (o), and health restrictions were also re-coded into having no restrictions (o) versus any restrictions (1).

Closeness and variation in closeness. Possible associations between the closeness of available friendships and loneliness trajectories were examined by the percentage of women with friends in different circles of the convoy at two points in time: directly after the intervention and one year later. The variation in closeness of friendship was studied by the number of circles of the convoy in which friends were present.

Changes in friendship. The changes reported by members of all three loneliness status groups were categorised into four types of possible change in friendship: gain, improvement, deterioration and loss.

The analyses of background characteristics, closeness of friends and variation in closeness, and changes in friendship were conducted using the chisquare test for independence.

\section{Results}

\section{Research question I}

From the cluster analyses of the loneliness scores at the end of the intervention and one year later, seven clusters of loneliness trajectories emerged as the most viable solution. The seven clusters are summarised in Table 2; we distinguish between non-lonely (scores less than 3), moderately lonely (scores $3^{-8}$ ) and very lonely participants (scores 9-11). Clusters 1 and 2 include those who were very lonely $(7 \%)$ or moderate lonely $(19 \%)$ initially, and who were no longer lonely after a year; in other words they had recovered from loneliness (very lonely recovered and moderately lonely recovered). Those who were very lonely $(15 \%)$ and reduced their loneliness by three points on average are located in cluster 3 (very lonely improved). Those who were moderately lonely and reduced their loneliness by an average of two points $(21 \%)$ are located in cluster 4 (moderately lonely improved). Cluster 5 includes those who remained very lonely $(20 \%)$; they are referred to as the very lonely stable. Cluster 6 includes those who were initially not lonely but who became moderately lonely $(9 \%)$ during the year after participation. Cluster 7 represents those who were not lonely (8\%) at both measurement points (non-lonely stable).

Based on the clusters of loneliness status, three different groups of persons could be distinguished: a Recovered group $(\mathrm{N}=28)$ consisting of clusters 1 and 2, an Improved group of clusters 3 and $4(\mathrm{~N}=39)$ and a 
T A B L E 2. Summary of cluster membership based on the loneliness scores at the end of the intervention and one year later

\begin{tabular}{|c|c|c|c|c|c|c|c|}
\hline & \multirow[b]{2}{*}{$\mathrm{N}$} & \multicolumn{2}{|c|}{$\begin{array}{l}\text { Loneliness at } \\
\text { the end of the } \\
\text { intervention }\end{array}$} & \multicolumn{2}{|c|}{$\begin{array}{l}\text { Loneliness } \\
\text { one year } \\
\text { later }\end{array}$} & \multirow{2}{*}{$\begin{array}{l}\text { Loneliness } \\
\text { change }\end{array}$} & \multirow{2}{*}{$\begin{array}{l}\text { Type of } \\
\text { group }\end{array}$} \\
\hline & & Mean & SD & Mean & $\mathrm{SD}$ & & \\
\hline \multicolumn{8}{|l|}{ Loneliness status: } \\
\hline 1. Very lonely recovered & 8 & 10.13 & 0.64 & 1.75 & 1.17 & $-8.3^{8}$ & Recovered \\
\hline $\begin{array}{l}\text { 2. Moderately lonely } \\
\text { recovered }\end{array}$ & 20 & $4 \cdot 60$ & 0.88 & 1.45 & 1 & -3.15 & group \\
\hline 3. Very lonely improved & 16 & $9 \cdot 75$ & 1.00 & $6.5^{6}$ & 0.81 & -3.19 & Improved \\
\hline $\begin{array}{l}\text { 4. Moderately lonely } \\
\text { improved }\end{array}$ & 23 & 6.91 & 1 & $4 \cdot 9^{6}$ & 1.67 & -1.95 & group \\
\hline 5. Very lonely stable & 22 & 10.23 & 0.87 & 9.95 & 0.9 & -0.27 & Non-improved \\
\hline $\begin{array}{l}\text { 6. Became moderately } \\
\text { lonely }\end{array}$ & 10 & 2.80 & 1.23 & 6.60 & 1.84 & 3.80 & group \\
\hline 7. Non-lonely stable & 9 & 1.00 & 0.87 & $0.5^{6}$ & 0.73 & -0.44 & Excluded \\
\hline Total & 108 & 6.94 & 3.26 & 5.06 & 3.45 & -1.77 & \\
\hline \multicolumn{8}{|l|}{ Types of group: } \\
\hline Recovered group & 28 & 6.18 & 2.67 & 1.54 & 1.04 & $-4 \cdot 39$ & \\
\hline Improved group & 39 & 8.08 & 1.72 & 5.62 & $1.5^{8}$ & $-2.4^{6}$ & \\
\hline Non-improved group & 32 & 7.91 & 3.63 & 8.91 & 2.01 & 1.00 & \\
\hline Excluded & 9 & 1.00 & 0.87 & $0.5^{6}$ & 0.73 & -0.44 & \\
\hline
\end{tabular}

Note: SD: standard deviation.

Non-improved group of clusters 5 and $6\left(\mathrm{~N}=3^{2}\right)$. Since the cluster of the non-lonely stable group $(\mathrm{N}=9)$ did not fit in one of these sub-groups and was very small, it was excluded from further analysis.

\section{Research question 2}

The results of the chi-square tests for independence indicated no significant association between loneliness status and the background characteristics of age, educational level, partner status and health restrictions. Table 3 illustrates that the differences in age and partner status between the Improved and the Non-improved group were small, as well as the differences on health restrictions between the Recovered and the Non-improved group.

\section{Research question 3}

The next step was to examine whether social resources, specifically the availability of different levels of friendship within the convoy, distinguished those who had recovered or improved from those who had not improved. 
T A B L E 3 . Comparison of loneliness status and background factors (significance of differences according chi-square test)

\begin{tabular}{|c|c|c|c|c|}
\hline \multirow[b]{2}{*}{ Background factors } & \multicolumn{3}{|c|}{ Loneliness status } & \multirow[b]{2}{*}{$\chi^{2}$} \\
\hline & Recovered group & Improved group & Non-improved group & \\
\hline \multirow[t]{2}{*}{$\mathrm{N}$} & 28 & 39 & 32 & \\
\hline & & Percentages & & \\
\hline Age: & & & & 1.19 \\
\hline$<65$ & $5^{\circ}$ & 62 & 63 & \\
\hline$\geqslant 65$ & $5^{\mathrm{O}}$ & $3^{8}$ & 37 & \\
\hline Education level: & & & & 6.63 \\
\hline Elementary & 29 & 39 & 31 & \\
\hline Secondary & 29 & $4^{6}$ & 44 & \\
\hline High & $4^{2}$ & 15 & 25 & \\
\hline Partner status: & & & & 1.34 \\
\hline No partner & 68 & 80 & 78 & \\
\hline Partner & 32 & 20 & 22 & \\
\hline Health restrictions: & & & & 1.06 \\
\hline No restrictions & 39 & 49 & 38 & \\
\hline Restrictions & 61 & $5^{1}$ & 62 & \\
\hline
\end{tabular}

An examination of the percentage of women with friends in different circles of the convoy directly after the intervention and one year later in Table 4 reveals that in all groups there was an increase in the proportion of women who included friends in the inner circle within a year after the intervention, with the greatest increase in the Recovered group (from 68 to $79 \%$ ). A chi-square test for independence indicated that the association between loneliness status and having friends in the inner circle of the convoy at the end of the intervention was almost but not quite significant $(p=0.057)$. A year later these associations between loneliness status and having friends in the inner circle had become significant (see Table 4).

There was also a slight increase in the inclusion of friends in the middle circle in both the Recovered (from 75 to $82 \%$ ) and the Improved group (from 67 to $74 \%$ ) within a year. In contrast, there was a decrease of friends in the middle circle for those in the Non-improved group (from 75 to $66 \%$; see Table 4). Despite these changes, the association between loneliness trajectories and having friends in the middle circles was neither significant at the end of the intervention nor a year after the intervention.

Changes in friendship in the outer circle demonstrate more variation (see Table 4). There is a slight decline in the Recovered group, a slight increase in the proportion of friends in the outer circle in the Improved group and a slight decrease in the Non-improved group. At both time-points, a clear majority of women in the Recovered and Improved groups had friends 
T A В LE 4. Loneliness status and percentage of women reporting having friends in the circles

\begin{tabular}{|c|c|c|c|c|c|}
\hline & \multicolumn{3}{|c|}{ Loneliness status } & \multirow[b]{2}{*}{$\chi^{2}$} & \multirow[b]{2}{*}{ Phi } \\
\hline & $\begin{array}{l}\text { Recovered } \\
\text { group }\end{array}$ & $\begin{array}{l}\text { Improved } \\
\text { group }\end{array}$ & $\begin{array}{l}\text { Non-improved } \\
\text { group }\end{array}$ & & \\
\hline \multirow[t]{2}{*}{$\mathrm{N}$} & 28 & 39 & 32 & & \\
\hline & \multicolumn{3}{|c|}{ Percentages } & & \\
\hline \multicolumn{6}{|c|}{ Friends in inner circle: } \\
\hline End intervention & 67.9 & 38.5 & $4^{6.9}$ & 5.8 & 0.24 \\
\hline One year later & 78.6 & $4^{6.2}$ & $5^{\mathrm{O}}$ & $7.8^{*}$ & 0.28 \\
\hline \multicolumn{6}{|c|}{ Friends in middle circle: } \\
\hline End intervention & $75^{\circ} \mathrm{O}$ & 66.7 & $75 \cdot 0$ & 0.081 & 0.09 \\
\hline One year later & 82.1 & $74 \cdot 4$ & $6_{5} .6$ & 2.12 & 0.15 \\
\hline \multicolumn{6}{|c|}{ Friends in outer circle: } \\
\hline End intervention & 82.1 & 59.0 & $37 \cdot 5$ & $12.27^{*}$ & 0.35 \\
\hline One year later & $75 \cdot 0$ & 64.1 & 28.1 & $15.19^{*}$ & 0.39 \\
\hline
\end{tabular}

Significance level: $* p<0.05$.

available in the outer circle in contrast to members of the Non-improved group. This association between loneliness status and having friends in the outer circle of the personal convoy was significant both at the end of the programme and one year later.

In Table 5 , the variation in closeness of friendship is represented by the number of circles of the convoy in which friends are present. A year after the programme there was a slight increase in the proportion of women reporting that they had friends in two or three circles, as well as a decrease in the proportion of women reporting friends in one or no circle, in both the Recovered and Improved group. In the Non-improved group there was an opposite development indicating an increase in the proportion of women reporting no friends in the convoy or in just one circle, and a decrease in the proportion reporting two or three circles with friends a year after the intervention. The association between loneliness status and number of circles with friends was significant both at the end of the intervention and one year later, indicating that having more variation in friendship is associated with a positive change in loneliness.

\section{Research question 4}

Four types of possible change in friendship (gain, improvement, deterioration and loss) were reported by members of all three loneliness status groups. The very high proportion of women reporting gain and improvement in friendship is striking among members of the recovered group. 
T A В LE 5. Number of circles with friends at the end of the intervention and one year later

\begin{tabular}{|c|c|c|c|c|c|}
\hline & \multicolumn{3}{|c|}{ Loneliness status } & \multirow[b]{2}{*}{$\chi^{2}$} & \multirow[b]{2}{*}{ Phi } \\
\hline & $\begin{array}{l}\text { Recovered } \\
\text { group }\end{array}$ & $\begin{array}{l}\text { Improved } \\
\text { group }\end{array}$ & $\begin{array}{l}\text { Non-improved } \\
\text { group }\end{array}$ & & \\
\hline \multirow[t]{2}{*}{$\mathrm{N}$} & 28 & 39 & 32 & & \\
\hline & \multicolumn{3}{|c|}{ Percentages } & & \\
\hline \multicolumn{6}{|l|}{ End intervention: } \\
\hline None & o & 5.1 & ${ }_{15} .6$ & $14.29^{*}$ & $0.3^{8}$ \\
\hline One circle & 17.9 & $43 \cdot 6$ & 28.1 & & \\
\hline Two circles & $39 \cdot 3$ & $35 \cdot 9$ & $34 \cdot 4$ & & \\
\hline Three circles & 42.9 & 15.4 & 21.9 & & \\
\hline \multicolumn{6}{|l|}{ One year later: } \\
\hline None & o & 2.6 & 18.8 & $20.18^{*}$ & $0.45^{2}$ \\
\hline One circle & 10.7 & 30.8 & $34 \cdot 4$ & & \\
\hline Two circles & 42.9 & 46.2 & 31.3 & & \\
\hline Three circles & 46.4 & 20.5 & 15.6 & & \\
\hline
\end{tabular}

Significance level: $* p<0.05$.

However, in all groups, at least $5^{\circ}$ per cent of the women reported making new friends, experiencing improvement in their friendships, as well as deterioration in friendship. Loss of friends was reported by about a third of the women in all three loneliness status groups.

The chi-square tests indicated that the association between loneliness status and specific friendship changes was not significant for making new friends, deterioration in friendship and losing friends. The only significant association was between loneliness status and improvement in friendship. In the Recovered group, women reported improvement in friendship more often than in the other two groups (see Table 6).

\section{Discussion}

The main goal of this study was to gain more insight into the diversity of long-term outcomes of women's own efforts to modify friendships and influence their loneliness during the year following their participation in the FEP. Previous analysis based on average scores of participants did not reveal the diversity of outcomes regarding loneliness that the cluster analysis in this study revealed. Within a year of completing the programme about one-quarter of the women were no longer lonely. Those who had recovered from the negative experience of loneliness included some who were severely lonely initially. More than one-third of the women had managed to reduce 
T A B L E 6 . Loneliness status and percentage of women reporting changing in friendship

\begin{tabular}{|c|c|c|c|c|c|}
\hline & \multicolumn{3}{|c|}{ Loneliness status } & \multirow[b]{2}{*}{$\chi^{2}$} & \multirow[b]{2}{*}{ Phi } \\
\hline & $\begin{array}{l}\text { Recovered } \\
\text { group }\end{array}$ & $\begin{array}{l}\text { Improved } \\
\text { group }\end{array}$ & $\begin{array}{l}\text { Non-improved } \\
\text { group }\end{array}$ & & \\
\hline \multirow[t]{2}{*}{$\mathrm{N}$} & 28 & 39 & 32 & & \\
\hline & 82.1 & $\begin{array}{l}\text { Percentages } \\
64.1\end{array}$ & 62.5 & $3 \cdot 31$ & 0.18 \\
\hline Improvement in friendship & $85 \cdot 7$ & $5^{1.3}$ & 50.0 & $10.32^{*}$ & 0.32 \\
\hline Deterioration in friendship & $64 \cdot 3$ & 53.8 & 65.6 & 1.24 & 0.11 \\
\hline Lost friends & $39 \cdot 3$ & 30.8 & $37 \cdot 5$ & 0.61 & 0.08 \\
\hline
\end{tabular}

Significance level: * $p<0.05$.

loneliness significantly, which presumably meant experiencing relief from some of the negative consequences of loneliness. In contrast to these groups of women, there was a sizeable minority who reported stable, high levels of loneliness during the year and a rather small group who became lonely during the year following the intervention, though they were not lonely at the end of the programme. There was also a small group who had not been lonely at the end of the programme, nor were they lonely a year later. For further analysis, we combined the clusters in a recovered group, an improved group and a non-improved group. The small cluster of women who were not lonely at both points in time were excluded from further analysis.

A second goal was to try to explain the variation in outcomes that were identified by contrasting those with positive change in loneliness with those without positive change. Resources involving education, the presence of a partner and health status were not associated with the loneliness patterns, nor was the participants' age. Selection effects may explain the absence of any associations between these variables and the patterns of loneliness, since women who attend the FEP are self-selected in response to information in folders and newspaper articles. Motivation to participate may be more important than educational level or health restrictions. The programme is designed for accessibility for a wide range of women of varying backgrounds without serious cognitive impairment. Although age appears to have no effect on loneliness patterns, the age range of the participants is limited to those between 55 and 80 , and the average age was about 63 , and therefore we cannot draw definite conclusions about the possible influence of age.

Finally, we examined whether those who were already socially advantaged in terms of the friendships available to them at the end of the programme 
might be more successful in reducing loneliness during the year studied. In order to satisfy the need to belong and avoid or reduce loneliness, a certain number of stable relationships which involve frequent contact, mutual affection and care are necessary (Baumeister and Leary 1995). Our results indicate that having at least one friendship in the outer circle of the convoy at the end of the intervention was more characteristic of those who would recover. Presumably this type of relationship is a source of companionship, but not intimacy; it may provide a certain base from which one can expand one's friendship network or improve the quality of friendship. The same association was found a year later for both the recovered and significantly improved, in contrast to the non-improved, indicating the importance of companionship for the relief of loneliness among older adult women. By the end of a year, the presence of an intimate friendship in the inner circle of the convoy distinguished those who did and those who did not recover from loneliness. Intimacy involving mutual affection, care and concern was more likely to be available in this type of friendship.

While having friends in the middle circle of the convoy does not in itself appear to affect loneliness, it may contribute to the variation in friendship as far as closeness and importance are concerned. It was clear that variation in friendship (having friends in two or three circles of the convoy) was a distinguishing characteristic of the recovered group, as opposed to the nonimproved, immediately after the intervention and a year later. Less variation in friendship was more characteristic among the non-improved group. These results confirm an important message of the FEP, which is that having a variety of friends, including both close and less close friends, contributes to wellbeing (Martina, Stevens and Westerhof 2012). Achieving variety in resources is also considered important for proactive coping (Bode et al. 2007) and for self-management of wellbeing (Steverink, Lindenberg and Slaets 2005).

Considering the possible ways that friendships can change, one might imagine that positive developments (e.g. making new friends and improving existing friendships) would be more characteristic of those who recovered or improved, and negative developments such as loss and deterioration in friendship would be more characteristic of those who either became lonely or remained very lonely (the non-improved group). It is noteworthy that rather high proportions of the women in all three groups reported acquiring new friendships, improvement in friendship and deterioration in friendship. The positive changes are likely a result of conscious efforts on the women's part to develop or improve friendships. Reports of deterioration in specific friendships may be the result of a greater awareness of one's needs and desires in friendship as a result of participating in the FEP. Failures in attempts to meet these needs in existing friendships and 
a greater awareness of friendships that are not satisfactory due to filling in a personal convoy several times may have caused a more negative evaluation of specific friendships. Some might argue that reporting a relatively high rate of deterioration in friendship is a negative effect of participating in the FEP. However, this may also indicate that participants became more selective in friendship, seeking interaction in more satisfactory friendships and reducing interaction in friendships that were not satisfactory. Presumably this leads to experiencing more positive wellbeing and reducing negative wellbeing among participants, as proposed by the socio-emotional selectivity theory (Carstensen, Isaacowitz and Charles 1999). Improvement in mood, that is, reporting more positive feelings and fewer negative feelings, was one of the effects of participation in the FEP (Martina and Stevens 2006).

Between 30 and 40 per cent of the women reported having lost friendships, due to death, debilitating illness of friends (e.g. dementia) or relocation. Loss of friends may be a normative life event in later life, since longitudinal research has demonstrated that friends are the relationship type most likely to leave the social networks as people age (Van Tilburg 1998; Wruz et al. 2013). Again the act of completing a personal convoy several times may have reminded participants of losses in friendship.

Among the various changes reported in friendship, it was only the experience of improvement in friendship which was more characteristic of those who had recovered from loneliness in comparison to the other two groups. One possible interpretation is related to relational competence; many of the women who had recovered may have already had, or succeeded in developing, more complex social skills that are useful for enhancing relationships (such as being able to share more personal experience, to demonstrate empathy and exchange emotional support, and to resolve conflicts). Apparently they were able to develop more intimacy in friendship (e.g. reporting friends in the inner circle more often) and were more likely to have and maintain more variation in types of friendship than those who did not show improvement with respect to loneliness (Hansson, Daleiden and Haylisp 2004). It is also possible that women who were successful in recovering from loneliness had friends who responded more positively to their attempts at improving friendship than did friends of others who did not report improvement. Since the essence of friendship is reciprocity, the input of both parties involved in the friendship is important for any positive qualitative change in the relationship (Hartup and Stevens 1997).

The feeling of loneliness among those with very high, stable loneliness scores is complex since it involves missing both companionship and intimacy (De Jong Gierveld, Van Tilburg and Dykstra 2006). It is possible that some of the women who experienced no relief from loneliness (or who 
became lonely) had tried but failed to establish either or both types of friendship, social and intimate. This experience may have reinforced existing loneliness or even have become a source of new loneliness. Their high stable loneliness may also have had other causes unrelated to the quality of their friendships. Interviews with these women reveal experiences involving enduring grief due to death of a partner, emotional turmoil following a recent divorce, conflicts or disappointment with children, as well as the desire for a new partner (rather than a new friend). In these cases, socialemotional selectivity in social relationships, as described by Carstensen, Isaacowitz and Charles (1999), may explain the absence of a reduction of loneliness or even the development of loneliness in the non-improved group. When those persons with whom one prefers interaction (such as a partner or children) are no longer or insufficiently available, one may experience loneliness that cannot be remedied by friendship. Although both theory on the need to belong (Baumeister and Leary 1995) and the social compensation model (Ferraro and Farmer 1995) assume that different types of relationships can be substituted for one another, this may not necessarily be true. It is clear that in order to understand the causes of high stable loneliness or an increase in loneliness, it is necessary to know more about the development of different types of relationships (with a partner, children, family and friends), the companionship and support that they offer, and the strains involved (Chen and Feeley 2014).

An important limitation of this study is the absence of baseline data, which was missing in one of the studies we used. Although it would have been interesting to analyse patterns of loneliness from the very beginning of the programme until a year after its completion, we believe that our analysis provides useful and unique information on important questions, such as: Is it possible for older adult women to recover from loneliness (including severe loneliness)? Are women with higher education more successful in reducing loneliness after participating in the intervention? Instead of studying the effectiveness of the intervention itself, we used a person-oriented approach to identify groups of participants who resembled one another in terms of change or stability in loneliness in the year following the programme, and who differed from other groups. We presumed that the patterns of loneliness during this period reflected the results of their own efforts to reduce loneliness.

Another limitation is that information on more personal characteristics (e.g. self-esteem, shyness, neuroticism or anxiety) that may contribute to development of and satisfaction with relationships, and thus with change and stability in loneliness (De Jong Gierveld, Van Tilburg and Dykstra 20o6), is not included in the analyses. There was some information on personal characteristics available in Study 2, that is, in half of the sample. A larger data-set with this kind of information would be useful to distinguish personal 
characteristics that are associated with change and stability in loneliness after completing the FEP. A final limitation is that both studies used the same self-reported measures on friendship availability and development, as well as on loneliness, so the influence of social desirability must be taken into account (Fisher and Katz 2000).

Despite the limitations, this study shows that using a person-oriented approach is valuable because it enabled us to identify differences in patterns of change or stability in loneliness over time that are not evident in variableoriented analyses. We were able to identify some characteristics of available friendships and developments in friendships that were associated with positive change, and specifically with the recovery from loneliness. The results motivate us to continue to offer this intervention to a wide range of women, since we did not find criteria that indicate that the programme is not suitable for some women (e.g. with a low educational level or with health restrictions). However, we need more insight in two groups, those who maintain high levels of loneliness and those who become lonely following the intervention. It is customary to offer referrals for participants who seem to require a different type of support to deal with their situation (e.g. psychotherapy for complex personal problems or bereavement counselling). Other types of interventions might be more suitable for some individuals, such as a personal coach who focuses on developing new forms of social engagement for those lacking the social advantages we have described as helpful. A limitation of this type of intervention is that not everyone is interested in participating in a group programme. An internet version of the FEP, designed for men and women age $5^{\mathrm{O}}$ and over, is in the process of being developed and tested. Although it appears that more recent cohorts of older adults do manage to maintain relations with friends and non-kin longer than in the past, there is still a sizeable group of older adults who never attained, or have tended to lose, these sources of diversity in their networks (Stevens and Van Tilburg 2011 ; Suanet, Van Tilburg and Broese van Groenou 2013). Therefore, it seems essential to continue to discover ways to support older adults in developing and maintaining supportive social networks that include reciprocal relations with both family, and friends or other non-kin; especially for those older adults who lack valuable resources for maintaining wellbeing and reducing or preventing the negative consequences of enduring loneliness as they age.

\section{Acknowledgement}

The study Friendship, Autonomy and Well-Being in Later Life was supported by ZonMw; The Netherlands Organization for Health Research and Development.

Ethical approval was not required. 


\section{References}

Baumeister, R. F. and Leary, M. R. 1995. The need to belong: desire for interpersonal attachments as a fundamental human motivation. Psychological Bulletin, 11 7, 3, $497-5^{28}$.

Bode, C., De Ridder, D. T. D., Kuijer, R. G. and Bensing, J. M. 2007. Effects of an intervention promoting proactive coping consequences in middle and later life. The Gerontologist, 47, 1, $4^{2-} 5^{1}$.

Cacioppo, J. T. and Patrick, W. 2008. Loneliness: Human Nature and the Need for Social Connection. W.W. Norton \& Company, New York.

Carstensen, L. L., Isaacowitz, D. M. and Charles, S. T. 1999. Taking time seriously: theory of socioemotional selectivity. American Psychologist, 54, 3, 165 6 -81.

Chen, Y. and Feeley, T. H. 2014. Social support, social strain, loneliness and wellbeing among older adults: an analysis of the Health and Retirement Study. Journal of Social and Personal Relationships, 31, 2, 141-61.

Cohen-Manfield, J. and Parpura-Gill, A. 2007. Loneliness in older persons: a theoretical model and empirical findings. International Psychogeriatrics, 19, 2, 279-94.

De Jong Gierveld, J. 1998. A review of loneliness: concept and definitions, determinants and consequences. Reviews in Clinical Gerontology, 8, 1, 73-8o.

De Jong Gierveld, J. and Kamphuis, F. 1985. The development of a Rasch-type loneliness scale. Applied Psychological Measurement, 9, 3, 289-99.

De Jong Gierveld, J. and Van Tilburg, T. 1999. Manual of the Loneliness Scale. Department of Social Research Methodology, Free University, Amsterdam. Available online at http://home.fsw.vu.nl/tg.van.tilburg/manual_loneliness_scale_1999.html [Accessed 21 November 2014].

De Jong Gierveld, J., Van Tilburg, T. and Dykstra, P. A. 2006. Loneliness and social isolation. In Perlman, D. and Vangelistis, A. (eds), The Cambridge Handbook of Personal Relationships. Cambridge University Press, Cambridge, $4^{8} 5^{-} 5^{\text {oo. }}$

Ferraro, K. F. and Farmer, M. M. 1995. Social compensation in adulthood and later life. In Dixon, R. A. and Backman, L. (eds), Compensating for Psychological Deficits and Declines: Managing Losses and Promoting Gain. Erlbaum, Hillsdale, New Jersey, $127-45$.

Fiori, K. L., Antonucci, T. C. and Cortina, K. S. 2006. Social network typologies and mental health among older adults. Journals of Gerontology: Psychological Sciences and Social Sciences, 61B, 1, 25-32.

Fisher, R.J and Katz, J. E. 200o. Social desirability bias and the validity of selfreported values. Psychology $\mathcal{E}$ Marketing, 1 7, 2, $105^{-20 .}$

Hansson, R. O., Daleiden, E. L. and Haylisp, B. 2004. Relational competence across the life span. In Lang, F. R. and Fingerman, K. L. (eds), Growing Together: Personal Relationships Across the Life Span. Cambridge University Press, Cambridge, 31 7-40.

Hartup, W. W. and Stevens, N. 1997. Friendships and adaptation in the life course. Psychological Bulletin, 121, 3, 355-70.

Hawkley, L. C. and Cacioppo, J. T. 2007. Aging and loneliness: downhill quickly? Current Directions in Psychological Science, 16, 4, 187-91.

Hawkley, L. C. and Cacioppo, J. T. 2010. Loneliness matters: a theoretical and empirical review of consequences and mechanisms. Annals of Behavioral Medicine, 4o, 2, $1-13$.

Huxhold, O., Miche, M. and Schüz, B. 2013. Benefits of having friends in older ages: differential effects of informal social activities on well-being in middle-aged and older adults. Journals of Gerontology: Psychological Sciences and Social Sciences, 69B, $3, \mathrm{~S}_{3} 66-75$. 
Kahn, R. L. and Antonucci, T. C. 1980. Convoys over the life course: attachment roles and social support. In Baltes, P. B. and Brim, O. (eds), Life Span Development and Behaviour. Volume 3, Academic Press, San Diego, California, 253-86.

Kremers, I. P., Steverink, N., Albersnagel, F. A. and Slaets, J. P. J. 20o6. Improved selfmanagement ability and well-being in older women after a short group intervention. Aging $\mathcal{E}^{2}$ Mental Health, 10, 5, 476-84.

Laursen, B. and Hoff, E. 20o6. Person-centerd and variable-centered approaches to longitudinal data. Merrill Palmer Quarterly, 52, 3, 377-89.

Litwin, H. and Shiovitz-Ezra, S. 2010. Social network type and subjective well-being in a national sample of older Americans. The Gerontologist, 51, 3, 379-88.

Luo, Y., Hawkley, L. C., Waite, L. J. and Cacioppo, J. T. 2012 . Loneliness, health, and mortality in old age: a national longitudinal study. Social Science $\mathcal{E} \mathcal{F}^{2}$ Medicine, 74, 6, 907-14.

Martina, C. M.S. and Stevens, N.L. 2006. Breaking the cycle of loneliness? Psychological effects of a friendship enrichment program for older women. Aging $\mathcal{E}$ Mental Health, 10, $5,467-75$.

Martina, C. M. S., Stevens, N. L. and Westerhof, G. J. 2012. Promotion of self-management in friendship. Aging $\mathcal{E}$ Mental Health, 16, 2, 245-53.

Oshri, A., Tubman, G., Wagner, E. F., Leon-Morris, S. and Snyders, J. 2008. Psychiatric symptom patterns, proximal risk factors, and sexual risk behaviours among youth in outpatient substance abuse treatment. American Journal of Orthopsychiatry, $\mathbf{7 8}, 4,430-41$.

Ouwehand, C. 2005. Proactive coping and successful aging. Unpublished doctoral dissertation, Utrecht University, Utrecht, The Netherlands.

Peplau, L. A. and Perlman, D. 1982. Perspectives on loneliness. In Peplau, L. A. and Perlman, D. (eds), Loneliness: A Sourcebook of Current Theory, Research and Therapy. Wiley, New York, $1-18$.

Pinquart, M. and Sörensen, S. $2001 a$. Gender differences in selfconcept and psychological well-being in old age: a meta-analysis. Journals of Gerontology: Psychological Sciences and Social Sciences, 56B, 4, P195-213.

Pinquart, M. and Sörensen, S. 2001 $b$. Influences on loneliness in older adults: a meta-analysis. Basic and Applied Social Psychology, 23, 4, 245-66.

Shaw, B. A., Krause, N., Liang, J. and Bennett, J. 2007. Tracking changes in social relations throughout late life. Journals of Gerontology: Psychological Sciences and Social Sciences, 62B, 2, S9o-9.

Sonnenberg, C. M., Beekman, A. T. F., Deeg, D. J. H. and Van Tilburg, W. 200o. Sex differences in late-life depression. Acta Psychiatrica Scandinavica, 101, 4, 286-92.

Stevens, N. 2001. Combating loneliness: a friendship enrichment programme for older women. Ageing $\mathcal{E}$ Society, 21, 2, 183-202.

Stevens, N. L., Martina, C. M. S. and Westerhof, G. J. 20o6. Meeting the need to belong: predicting effects of a friendship enrichment program for older women. The Gerontologist, 46, 4, 495-5 ${ }^{\mathrm{O} 2}$.

Stevens, N. L. and Van Tilburg, T. G. 2011. Cohort differences in having and in retaining friends personal networks in later life. Journal of Social and Personal Relationships, 28, 1, 24-43.

Stevens, N. L. and Westerhof, G. J. 20o6. Partners and others: social provisions and loneliness among married Dutch men and women in the second half of life. Journal of Social and Personal Relationships, 23, 6, 921-41.

Steverink, N., Lindenberg, S. and Slaets, J.P.J. 2005. How to understand and improve older people's self management of wellbeing. European Journal of Aging, 2, $4,235^{-44}$. 


\section{Camille M. S. Martina et al.}

Suanet, B., Van Tilburg, T. G. and Broese van Groenou, M. I. 2013. Nonkin in older adults' personal networks: more important among later cohorts? Journals of Gerontology: Psychological Sciences and Social Sciences, 68B, 4, 633-43.

Van Tilburg, T. G. 1998. Losing and gaining in old age: changes in personal network size and social support in a four-year longitudinal study. Journals of Gerontology: Social Sciences, 53B, 6, S313-23.

Wruz, C., Hänel, M., Wagner, J. and Neyer, F. J. 2013. Social network changes and life events across the life span: a meta-analysis. Psychological Bulletin, 139, 1, 53-80.

Accepted 3 August 2016; first published online 2 November 2 о I6

Address for correspondence:

Camille Martina,

Department of Developmental Psychology \& Psychogerontology,

Radboud University,

P.O. Box 9104,

$6_{5}$ oo HE Nijmegen, The Netherlands

E-mail: c.martina@psych.ru.nl 